\title{
La elaboración de la Ordenanza de Montes de Marina, de 31 de enero de 1748, base de la política oceánica de la monarquía española durante el siglo XVIII/*
}

\section{The development of the forest Ordinance for the Navy, 31st January 1748, the oceanic political basis of the Spanish monarchy during the eighteenth century}

Alfredo José Martínez González

Universidad de Sevilla

Este estudio pretende analizar, desde una perspectiva jurídico-institucional, los diversos trabajos preparatorios que abordó la Monarquía española con objeto de crear, en 1748, una Ordenanza forestal para fomento naval, que compitió con las necesidades de las poblaciones rurales que veían cómo les era despojada su materia prima cotidiana, extraída de los árboles.

Palabras Claves: Armada; Barcos; Árboles; Bosques; Montes; Madera; Ordenanza; 1748.

The aim of this study is to analyze, from a legal and institutional perspective, the several preparatory work done by the Spanish monarchy in order to create, in 1748, a forest Ordinance for naval construction that competed with the needs of the rural populations who saw how their daily raw material, extracted from the trees.

KEYWORDS: Navy; Boats; Trees; Forest; Woods; Timber; Ordinance; 1748.

* Mi agradecimiento al Dr. Adolfo Luis González Rodríguez, americanista y maestro. 


\section{Introducción}

«El mayor punto del comercio de España depende de arreglar lo casi perdido con sus Indias, mientras el mal gobierno que ha habido por el pasado en el Comercio de Indias, ha sido causa del gran poder de la Inglaterra, Holanda, y Francia, y ha traído por consiguiente la flaqueza y decadencia de esta Monarquía».

«Tienen Señor tanta conexión entre sí la Navegación, y el Comercio que es imposible que la una esté floreciente en su Estado, no estándolo la otra, ni recíprocamente podrían subsistir».

«Siempre Señor han temido las Potencias que esta Monarquía despierte de una vez, y ponga los medios fáciles que tiene de formar una Armada de Mar porque aun con la España y las Indias, teniendo V.M. Armada Naval se hará dueño de todo el tráfico y destruirá el poder de otras Potencias, y V.M. se hará el árbitro de la paz y de la Guerra».

Sin duda estas contundentes reflexiones reflejan con absoluta nitidez las inquietudes y desvelos a los que debió hacer frente desde múltiples perspectivas, también la jurídica, la monarquía hispánica durante el siglo XVIII para poder cohesionar y conciliar los dos principales soportes sobre los que ésta se asentaba: en primer lugar, la integridad territorial $\mathrm{y}$, en segundo lugar, el comercio marítimo, especialmente en su relación con las tierras americanas. ${ }^{2}$ Éstos serán el leitmotiv de todo un programa de política exterior que se vio sustentado con recursos interiores a costa de un elevado precio, no sólo económico, sino que también debieron pagar con enormes extensiones de terrenos boscosos. ${ }^{3}$

Es sabido que tras el declive naval experimentado durante las últimas décadas de los Austrias, la carrera de otras potencias con intereses en el Nuevo Mundo por construir y armar navíos fue denodada. ${ }^{4}$ Esta progresiva actividad exigió no sólo recursos técnicos y económicos, sino también el impulso y perfeccionamiento de las gestiones forestales, puesto que la madera era el principal recurso para la fabricación de naves. Tan estratégica

1 Los tres pasajes son anónimos. Únicamente se sabe que fueron transcritos, en 1792, por el marino e historiador Martín Fernández de Navarrete, dentro de un extenso memorial dirigido a Felipe $\mathrm{V}$ en 1725. Archivo del Museo Naval (AMN), Colección Fernández de Navarrete, IX, doc. 39. Representación hecha a S. M. sobre el Estado del Comercio y Marina y forma fácil de su mayor y respectivo adelantamiento, en Madrid año de 1725, 415r., 448v. y 450r.

2 Béthencourt Massieu, 1998, 33 y 586.

3 Urteaga, 1987, 115.

4 Diego García, 2002, 15-17. 
fue esta materia prima que su obtención o escasez condicionó irremediablemente el poderío o la languidez de las flotas, así como propició la adopción de estrictas medidas normativas para evitar la deforestación que su uso provocaba desde la dinastía de los Habsburgo. ${ }^{5}$ Antes del siglo XVIII, la Monarquía Hispánica se había aferrado a un antiguo régimen basado en la diseminación de astilleros, pero que ya se mostraba ineficaz ante los avances técnicos. ${ }^{6}$ Por otro lado, hasta la llegada de los Borbones, el arco cantábrico había sido tradicionalmente el área tradicional abastecedora de maderas para la construcción de navíos destinados, entre otras latitudes, a la Carrera de Indias, afectando las talas sobre los órganos locales y la economía de subsistencia del común de los vecinos, y encontrándose esquilmado como consecuencia tanto de la fabricación de naves como por el consumo de carbón de las ferrerías que las nutrían de armamentos. ${ }^{7}$

\section{Las primeras medidas jurídicas, administrativas y estructurales}

Aunque de modo tardío y tras sobreponerse a la crisis generada por la Guerra de Sucesión, España se unió a la pugna constructiva con cierto e inesperado éxito, gracias a las medidas administrativas, legislativas e institucionales impulsadas por el secretario de Marina, José Patiño, desde 1717 hasta su fallecimiento, en $1736 .^{8} \mathrm{~A}$ estas alturas resultaba esencial recobrar las comunicaciones con la América Hispana y asegurarse el control sobre éstas. ${ }^{9}$ Dentro de la multiplicidad normativa que se produjo tras la Guerra de Sucesión, encaminada al fomento naval, se encontraron normas cuya temática resulta elocuente, tales como Reglamentos y Ordenanzas en materia de comercio y navegación con las Canarias y América, de 16 de diciembre de 1718 y 5 de abril de 1720, o sobre soldadas a percibir por las tripulaciones de mercantes con destino a Indias, de 9 de diciembre de $1723 .{ }^{10}$ Como no podría ser de otra manera, esta progresiva actividad de fomento naval exigió no sólo recursos técnicos y económicos, sino también el impulso y perfeccionamiento de las gestiones silvícolas. A él se debe en

5 Casado Rabanal, 2009, 64-66.

6 Rodríguez-Villasante, 1990, 501

7 Respecto del devenir del esquilmo forestal por consumo de las ferrerías, ver Díez de Salazar Fernández, 1983.

8 Sobre la labor jurídico-administrativa de José Patiño, ver Martínez González, 2013.

9 García-Baquero, 1976, 103-132; Fisher, 1994, 24-25.

10 Rumeu de Armas, 1989, 59. 
buena medida la reorganización de una Nueva Planta en la Marina acerca de la que hemos de detenernos, al menos someramente, para poder comprender conceptos sobre los que posteriormente orbitó la Ordenanza forestal de 1748 .

Bajo el mandato de Patiño se establecieron profundas modificaciones administrativas y jurídicas que trascendieron en el tiempo, soslayando la concurrencia de simples astilleros y pasando todo el proceso fabril naval por arsenales, a semejanza de la política seguida en Francia desde la segunda mitad del seiscientos. ${ }^{11}$ En estas instalaciones se recibía la madera talada o comprada por la Marina para la construcción y carenado de los navíos, además de almacenar todo tipo de pertrechos, municiones, materiales y géneros al servicio de la Armada, ${ }^{12}$ pudiendo ser considerado como un extenso «complejo industrial» ${ }^{13}$ mucho más completo que las anticuadas factorías. Su funcionamiento y orden quedaron regulados mediante una Instrucción General, de 1 de mayo de 1723, conocida también como «Ordenanza de Arsenales», ${ }^{14}$ debiendo residir en ellos un «Ministro Subdelegado del Intendente» ${ }^{15}$ y contando con personal especializado, que trabajaba bajo la dirección de un técnico de la materia, que constituía el cuerpo de la Maestranza, ${ }^{16}$ siendo esencial la Maestranza de madera debido a su importancia. Ello supuso el inicio de exploraciones, protagonizadas por personal militar de diversa graduación y otros trabajadores de cada arsenal, a extensas áreas de montes maderables para calcular las posibilidades forestales con las que podía contar la Marina. ${ }^{17}$

11 Díaz Ordóñez, 2009, 181.

12 Sobre la descripción de los arsenales: Archivo Histórico Nacional (AHN), Estado, 3228/2, Idea del estado de la Marina de España, y lo que parece conveniente a su buen régimen, y fomento. Año de 1776.

13 Diego García, 2009, 30.

14 Instrucción General de lo que en los asuntos gubernativos, políticos, y económicos se ha de observar, determinantemente en los Arsenales de Cádiz, y en los de Ferrol, y Cartagena, con reflexión a que los Intendentes deben residir en sus propios Arsenales: Que las funciones del Contador que se llama de ellos, las deben suplir en Ferrol y Cartagena sus Contadores de Marina; y que en estos Departamentos los Guarda-Almacenes Generales lo han de ser también de Artillería, y los de Depósitos de lo excluido. Hemos empleado una reedición de la misma que se halla en la Real Academia de la Historia (RAH), 9/5522 (6), fechada en Buen Retiro, febrero de 1737. Encontramos un ejemplar incompleto de la edición de 1723 en el Archivo del Museo Naval (AMN), Ms 2139-5. En la carpetilla de su portada aparece como «Instrucción original de Arsenales. Comprado, entre porción de papeles, en Sevilla, en 1862. Comprende solo los 34 puntos primeros y carece de final». Éste coincide en los artículos que preserva con la reedición arriba empleada, conservada en de la Real Academia de la Historia.

15 RAH, 9/5522 (6), Art. 1.

16 Pérez-Crespo Muñoz, 1992, 79.

17 Aranda y Antón, 1990, 19. 
Por su parte, las actuaciones silvícolas que debían emprender los oficiales se diseñaron de manera colegiada, completándose las disposiciones de 1723 con las «Ordenanzas e Instrucciones generales, formadas de real orden, de lo que se debe observar por los Intendentes, y demás Ministros de Marina, y dependientes del Ministerio de ella, según lo respectivo al empleo, y encargo de cada uno, para la mejor administración de la Real Hacienda, y cuenta, y razón de ella», de 1 de enero de $1725 .{ }^{18}$ Éstas regularon, mediante treinta y un capítulos, los cometidos del personal administrativo al servicio de la Marina que prestaba sus servicios en tierra, también respecto de la gestión forestal, y destacando el cargo del Intendente ${ }^{19}$ Esta figura, podía tener una doble naturaleza. En un primer plano, el Intendente General de la Marina de España, dentro de cuyas competencias se encontraban los asuntos de «Montes, sus Cortas, y Plantíos». ${ }^{20} \mathrm{~A}$ éste le acompañaban, en segundo lugar, los Intendentes particulares de los puertos y sus funciones abarcaban todo lo concerniente a la economía, policía, y Real Hacienda de su distrito, así como tener a su cargo todos los Comisarios Ordenadores, y Ordinarios que se le destinaren. ${ }^{21}$ También, entre otros asuntos, el apresto de navíos, que abarcaba las cuestiones silvo-madereras, ${ }^{22}$ facultándosele para la administración de justicia, «civil y criminal», en todos los asuntos relacionados con sus competencias. $^{23}$

$\mathrm{Al}$ establecimiento de arsenales le acompañó otra medida administrativa de enorme repercusión: la creación, por Real Orden de 5 de julio de 1726, de tres Departamentos marítimos, también, como hemos dicho antes, de inspiración francesa, ${ }^{24}$ a los que quedarán vinculadas enormes extensiones de montes y plantíos. Éstas circunscripciones se definían como «El distrito de la costa a que se extiende la jurisdicción o mando de cada capitán o comandante general e intendente de Marina establecidos en los tres puntos de Cádiz, Ferrol y Cartagena para los negocios del ramo».$^{25}$ Dentro de cada Departamento cada intendente tenía las supremas

18 Hemos empleado la reedición conservada en la Biblioteca del Museo Naval de Madrid (BMN), 2008.

19 Pérez Fernández-Turégano, 2006, 109-112.

20 BMN, 2008, Cap. I. Art. 1.

21 Ibidem, Cap. II. Art. 1.

22 Ibidem, Cap. II. Art. 3.

23 Ibidem, Cap. II. Art. 18.

24 Crespo Solana, 2004, 186.

25 O'Scanlan, 1831, 208. 
competencias en Montes, de acuerdo con las Ordenanzas de 1725 y siendo ratificadas mediante otra nueva Ordenanza de 19 de julio de $1735 .{ }^{26}$

En cuanto a su ámbito territorial, cada Departamento abarcaba enormes extensiones. El Ferrol, se extendía desde Portugal hasta la frontera con Francia; Cádiz, desde la portuguesa hasta Almería, además de Canarias; Cartagena, desde Murcia hasta el límite con Francia, más Baleares. Por su parte, cada Departamento, cuyo núcleo lo constituía su respectivo arsenal, se encontraba dividido en diversas provincias marítimas. ${ }^{27}$ Así las cosas, estas nuevas circunscripciones alcanzaron una enorme trascendencia en la gestión y explotación por parte de la Armada en los bosques de cada una de las jurisdicciones a su cargo. ${ }^{28}$

La desaparición de Patiño, dada la enorme trascendencia del personaje, supuso un viraje en la política oceánica de los Borbones, incluyendo la faceta silvícola. Su deceso coincidió con la restauración ad hoc de la institución del Almirantazgo, reunida en una sola persona, la del Infante D. Felipe, quien ostentaría el mando supremo de la Armada. ${ }^{29}$ Su génesis tuvo lugar mediante Real Cédula, otorgada en el Pardo, el 14 de marzo de $1737^{30} \mathrm{y}$, aunque en este documento de fundación no existe ninguna referencia expresa a la materia forestal, es lo lógico suponer que al concederse al infante don Felipe plenos poderes en todo lo relativo a la Marina, esta disposición propiciara que el Almirantazgo abarcase las cuestiones relativas a los montes útiles para el Real Servicio. Sea como fuere, se trató de un otorgamiento de poderes muy amplio en favor de la institución reestablecida pero con contornos poco nítidos, lo que hizo que se produjesen inevitables conflictos competenciales respecto a los bosques entre el cargo del infante y la preexistente Secretaría de Estado y el Despacho de Marina e Indias. ${ }^{31}$ Todas estas fricciones fueron atajadas mediante la Real Cédula de

26 Pérez Fernández-Turégano, 2006, 120-121.

27 Ibidem, 116.

28 Díaz Ordóñez, 2009, 22.

29 El anterior Almirantazgo había sido creado en 1624 persiguiendo la colaboración con los comerciantes y la administración de los Países Bajos españoles, cerrando el paso a todas las mercancías y navíos enemigos (Israel, 1990, 121-122). No obstante, existieron diferencias de relevancia respecto de la anterior institución homónima, relativas sobre todo al ámbito competencial. La primera se encargaba fundamentalmente de la represión del contrabando. Vid. Baltar Rodríguez, 1998, 248. de 1737.

30 Real Academia de la Historia (RAH), 9/5522 (8), Real Cédula, El Pardo, 14 de marzo

31 La Secretaría que se ocupaba de los asuntos de Marina había sido creada años antes, mediante Decreto de 30 de noviembre de 1714. Perona Tomás, 1999, 46-56 
14 de enero de 1740, que finalmente sí atribuía al Almirante General de la Marina, entre otros cometidos:

vigilar a la conservación, y aumento de los Montes, y Plantíos, como tan importantes para las Construcciones, y carena, a cuyo fin daréis las ordenes, y instrucciones convenientes a los Intendentes de los Departamentos, y demás Ministros a quienes toque. ${ }^{32}$

Así pues, además de ostentar facultades jurisdiccionales, la institución del Almirante también se encargaba de los aspectos más operativos y prácticos de la Armada, entre los que se encontraban expresamente las masas forestales útiles para la Marina, ${ }^{33}$ provocando que la Secretaría quedase relegada durante ciertos años a un segundo plano. Por su parte, en el mismo año de su fundación, en 1737, fue promovido al cargo de secretario del Almirantazgo Zenón Somodevilla Bengoechea. ${ }^{34}$ La designación de Ensenada no fue una cuestión menor porque a la postre se convertirá en el alma mater de la institución,$^{35}$ contribuyendo a la reorganización completa de la Marina de guerra mediante reglamentos e instrucciones que establecieron las líneas maestras del nuevo sector naval ${ }^{36} \mathrm{y}$, consecuentemente, repercutiendo sobre el ámbito forestal.

Por su parte, y dentro de esta duplicidad de instituciones, a Patiño le siguieron en la Secretaría de Marina, Mateo Díaz de Labandero (17361739), José de Quintanilla (1739-1741) y José del Campillo y Cossío (1741-1743) ${ }^{37}$, ninguno de los cuales logró hacer frente contundentemente a las operaciones contrabandistas inglesas en las costas americanas. Antes al contrario, el conflicto se agravó con la Guerra de la Oreja de Jenkins (1739-1748), auténtico conflicto colonial que supuso un doble problema para la Monarquía Hispánica, afectando tanto a la seguridad como al comercio. $^{38}$

Así las cosas, durante los años en los que el Almirantazgo se convirtió en el verdadero órgano de gobierno de los asuntos navales, hasta el comienzo de su progresiva desaparición a principios de la década de los

32 Pérez Fernández-Turégano, 2004, 450.

33 AHN, Estado, 5002, Real Cédula, El Pardo, 14 de marzo de 1737.

34 Lynch, 2010, 143-145.

35 Pérez Fernández-Turégano, 2004, 437 y 464.

36 Díaz Ordóñez, 2009, 130.

37 Rumeu de Armas, 1989, 31.

38 Lynch, 2010, 137-138. 
años cuarenta, ${ }^{39}$ la Secretaría quedó reducida a un papel muy limitado. ${ }^{40}$ Lo que parece claro es que a pesar de las necesidades navales, durante las primeras décadas de la dinastía borbónica no se diseñó ninguna disposición que abarcase homogéneamente a las diferentes regiones de la Monarquía y se ocupara de las situaciones suscitadas a raíz de unas talas y plantíos para construcción naval que, como contrapartida, afectaban a una economía rural que basaba buena parte de su subsistencia en la silvicultura.

\section{Reconocimientos y sondeos desde el sur peninsular hacia el resto de la Península}

En el siglo XVIII la necesidad de materiales para los navíos de línea era mucho mayor que en el caso de los antiguos galeones y se precisaban muchos barcos. Para poderlos dotar de un abastecimiento adecuado la Monarquía entendió que era necesaria una norma unitaria que abarcase todos los territorios susceptibles de proporcionar maderas útiles. Sin embargo, los intentos y preparativos no fueron una cuestión sencilla. Las partidas de troncos y tablas que se emplearon hasta finales de los años cuarenta fueron tan diversas como heterogéneas en lo que a la procedencia y al tipo se refiere. A eso ha de añadírsele la falta de un suministrador estable, lo que se tradujo en una alta provisionalidad y precariedad..$^{41}$ Esto quedó reflejado en un informe, fechado en el arsenal del Departamento gaditano de la Carraca el 4 de agosto de 1737, que calculaba detalladamente la cantidad de maderas necesarias para que las instalaciones estuviesen suficientemente abastecidas. ${ }^{42}$ Aquellas, a su vez, debían ser de diferentes áreas en función de la zona del barco a la que se destinaran: robles de los

39 El ocaso de la institución comenzó en 1741, fecha en la que el Infante don Felipe acudió a las campañas de Italia. En 1743 se decidió suprimir la Secretaría del Almirantazgo, quedando tan sólo la figura del lugarteniente. En aquellos momentos la institución ya había pasado a tener «casi un carácter honorífico», lo que supuso su desaparición fáctica para, el 30 de octubre de 1748, extinguirse por completo. Al respecto: Mateos Dorado, 1993, XLIV; Pérez Fernández-Turégano, 2004, 470-472; Díaz Ordóñez, 2009, 131.

40 Pérez Fernández-Turégano, 2004, 131.

41 Quintero González, 2004, 391.

42 AGS, Secretaría de Marina, 553, Estado de las Maderas que D. Antonio González de Marroquín Capitán de fragata. Interino de la Maestranza. considera ser menester para Provisión de estos Arsenales. a fin de que no se experimente falta en las Carenas y Armamento de los Bajeles del Rey, y con distinción de el Numero de Piezas gruesos y Largos que deben tener, La Carraca, 4 de agosto de 1737 . 
montes próximos a Málaga y costa de Cantabria, arboladuras de Flandes o de Tortosa, álamos y pinos de las cercanías de Sevilla y condado de Niebla, así como tablas para forros provenientes de la Sierra de Segura.

Es de resaltar la cantidad ingente de maderas que era necesaria para una obra naval y que requería de una amplia cobertura legal, propiciadora del acopio sistemático de maderas. Ello redundaba obligatoria y considerablemente en detrimento de las masas forestales, sobre todo si éstas no se veían dotadas adecuadamente de plantíos que reemplazasen los ejemplares arrancados. A este respecto, efectuar cálculos sobre el número de árboles precisos para construir las embarcaciones de línea no deja de ser una labor arriesgada puesto que las proporciones, coeficientes y demás parámetros oscilan en función de factores muy diversos. Aún así, un destacado oficial del Departamento de Cádiz y constructor naval, Ciprián Autrán ${ }^{43}$ calculaba una media aritmética de 2.574 árboles para un navío de 70 cañones y 3.516 ejemplares para uno armado con $80 . .^{44}$

Ello justifica las enormes cantidades de maderas que se precisaban para la construcción de embarcaciones y la correlativa deforestación que podía provocar la política marítima. Por esta razón fueron efectuados ciertos trabajos, encomendados a oficiales de la Armada, encaminados a reconocer los terrenos que abastecieran la Marina dieciochesca y sobre los que debía versar la esperada norma.

La primera de las actuaciones que tenemos noticia tuvo lugar el 16 de junio de 1734. En esa jornada Patiño decidió enviar a Ciprián Autrán a reconocer los bosques de la jurisdicción de Málaga y los pertenecientes al Campo de Gibraltar a fin de que describiese, catalogase y enumerase qué maderas podían ser útiles para el Real Servicio. Conjuntamente debía ordenar su envío al arsenal gaditano para proveerlo del máximo número de troncos y tablazones. Además, para poder llevar a efecto esta pretensión debía reconocer cuáles eran las vías fluviales o terrestres que más facilitasen su traslado. Autrán concluyó con éxito su trabajo realizando un exhaustivo informe en el que llegó a contabilizar más de 30.000 árboles útiles para arquitectura naval. ${ }^{45}$

Pocos años después, en 1738, un intendente, Alejo Gutiérrez de Rubalcaba, entregó al Almirantazgo una relación, con carta de 11 de Junio,

43 Quintero González, 2004, 422-423. Madoz define a Autrán como «director general de la construcción en España». Madoz, 1847, 50.

44 Aranda y Antón, 1990, 57.

45 Quintero González, 2004, 398-406. 
sobre el Reconocimiento que hizo el maestro mayor de Arboladura del Arsenal de Cartagena acerca de los Montes de la Sierra de Segura, la calidad de sus pinos y el curso del río del mismo nombre, y planos de su cauce desde el nacimiento hasta su desembocadura en el Mediterráneo. ${ }^{46}$ Sobre esta zona debemos detenernos, pues a posteriori adquirirá una importancia estratégica en la gestión forestal de la Marina. Así el roble, especie muy codiciada para el casco y buena parte de las piezas de las naves, era poco frecuente en aquellos montes, al contrario que el pino, que no sólo era abundante sino también estimado para la fábrica naval, puesto que, aunque no se utilizaba para la construcción de los cascos, el informe, de 4 de agosto de 1737, precisa que podía servir para la obra interior de los navíos y otras actividades complementarias de los arsenales. Esto hacía muy atractivas sus maderas al tener además en cuenta que, debido a sus cantidades, su coste era relativamente barato. La distancia que existía entre dicho macizo montañoso y el litoral marítimo era enorme. Por ello su explotación tal vez hubiese sido ilógica de no concurrir en la zona un decisivo factor simplificador: su comunicación con la costa no suponía excesivas complicaciones puesto que tanto el río Guadalimar como el Guadalquivir facilitaban el transporte de sus maderas. ${ }^{47}$

Paradójicamente, la actividad maderera por parte de la Monarquía Hispánica sobre estos montes no comenzó como consecuencia de las necesidades navales, sino a raíz de la construcción la antigua Fábrica de Tabacos de Sevilla, creándose en el año de 1733 el Real Negociado de Montes o Maderas de Segura, radicado en Sevilla y con subdelegación en Orcera, arrabal de la población de Segura de la Sierra. ${ }^{48}$ Tras las primeras actuaciones del Negociado la Marina también puso sus miras en aquellas masas forestales y, al menos desde finales de 1737 o principios de 1738, el arsenal de la Carraca se vio provisto de maderas nacidas en Segura, tal vez adquiridas de las existencias con las que comerciaba el propio Negociado. Como consecuencia, desde la Intendencia de Cádiz, se comunicó a Ensenada meses antes del Reconocimiento de junio de 1738 la utilidad de

46 AMN, 64-185, Misiva de Alejo Gutiérrez de Rubalcaba a Zenón Somodevilla, Madrid, 19 de junio de 1738. La Sierra de Segura o Sierras de Segura, también conocidas como Montes de Segura, eran y siguen siendo el topónimo orográfico que designa el conjunto montañoso ubicado entre el sector oriental de la actual provincia de Jaén, el occidental de Albacete y el noreste de Granada. Vid. Cruz Aguilar, 1987, 226.

47 Merino Navarro, 1981, 198-199.

48 AGS, Secretaría de Marina, 557, Informe, Segura de la Sierra, 17 de marzo de 1752. Cruz Aguilar, 1987b, 229-230. 
explotar aquellos bosques. ${ }^{49}$ Así, es comprensible que por todos los beneficios que la Sierra de Segura podía proporcionar a la Marina, el intendente, Gutiérrez de Rubalcaba, expusiese al marqués de la Ensenada:

lo conveniente que seria cuidar de la conservación de estos, por a lo menos la tabla ordinaria se podría sacar de ellos con ventajas en el costo a la del norte solicitando VS. al propio tiempo se advierta por el presidente del Consejo de Ordenes al Gobernador de Segura, que cele la conservación de los montes y ha practicar lo mismo a las Justicias de los Lugares de Su Gobernación para remediar los desordenes que se cometen en ellos..$^{50}$

Esta petición fue aceptada y se le ordenó al gobernador de la Sierra «que por todos medios cuide de advertir y celar, cuanto conduzca y le parezca conveniente a la Conservación de aquellos montes».

Además, en la misma comunicación Rubalcaba se mostró preocupado por atajar en los bosques de la jurisdicción de Cartagena frecuentes incendios con el pretexto de tener pastos para los ganados, así como talas continuadas con la finalidad de obtener terrenos para siembra «sin que por parte de Vm ni de las Justicias de los lugares que están inmediatos se haga cuidado de reparar estos desordenes de los cuales se siguen gravísimos perjuicios al Real Servicio», quedando de manifiesto la existencia de conflictos por la confluencia de usos. En respuesta, se le previno que atajase los excesos advirtiendo «a las Justicias de los Lugares inmediatos a ellos invigilen en lo propio, y que así estas como VM ejecuten cuanto sobre este particular les comunique», pretendiendo evitar una yuxtaposición entre las jurisdicciones locales y las de Marina.

La conveniencia por la Sierra de Segura se plasmó poco después en la visita que el capitán de fragata y teniente de la capitanía de Maestranza, Juan Valdés y Castro hizo a la zona a comienzos de verano con el fin de tantear la utilidad efectiva de sus árboles. Su labor no pudo desempeñarla cómodamente, al menos si pretendió obtener la colaboración de sus habitantes, puesto que «no encontró en Segura quien quisiere entrar en el asunto de las maderas». ${ }^{51}$ A pesar de la poca asistencia prestada, poco tiempo después emitió dos informes acerca del interés de la materia prima en

49 AGS, Secretaría de Marina, 553, Carta de la Intendencia de Cádiz a Ensenada, La Carraca, 21 de enero de 1738 .

50 AMN, 64-185, Alejo Gutiérrez de Rubalcaba a Zenón Somodevilla, Madrid, 19 de junio de 1738 .

51 AGS, Secretaría de Marina, 552, La Carraca, 30 de junio de 1738. 
aquella área. El primero fue titulado Prevenciones sobre la utilidad que podrá tener a la Real Hacienda, Servirse de los Arboles, y demás maderas de Pino cortadas y que pueden Cortarse en los montes y Sierras de Segura, $Y$ que teniendo presentes los parajes en que se hallan con menos dificultad, de sacarse dellos, y mas aptitud de Conducirse a estos Arsenales, de Carraca para emplear en las carenas de los Navíos que reparan en su Caño y se hacen por mi..$^{52}$ El segundo apareció como Derrotero del río Segura hasta la desembocadura en el Mediterráneo, abundancia de agua que lleva, malos pasos, vueltas y revueltas que puedan impedir el de las maderas y árboles de pino, por si conviniese facilitarlo navegable. En este último indicó igualmente cuáles eran los bosques de aquel territorio, su clasificación, medición y el justiprecio de los árboles útiles para la Monarquía ${ }^{53}$ En ellos no sólo trataba de las cantidades de maderas adecuadas para el Real Servicio, sino también de las posibilidades que existían para abrirse caminos, haciendo especial hincapié en las rutas que pudiesen discurrir por terrenos pertenecientes al monarca y en la gratuidad de sus maderas, argumentando «ser los Sitios realengos». Además, expuso todo el proceso que debería seguirse para el transporte fluvial de los troncos por los ríos Guadalimar y Guadalquivir.

Por otro lado, resulta de interés un encargo más de reconocimiento de montes que también se hizo al Departamento de Cádiz para inspeccionar las masas forestales del noreste peninsular. Con esta intención el intendente, Francisco de Varas, le confirió a Juan Valdés, una instrucción «para ejecutar el reconocimiento de los Pinos que se encuentren en los Montes de Cataluña para actos de arboladura y tablazón». ${ }^{54}$ Pero además, de la correspondencia existente se deja entrever una intención futura. Nos referimos a la posibilidad de extender la aprehensión de maderas a otras partes de la península que aún no estuviesen explotadas por la Marina pero que pudieren ser útiles.

La vía más rápida para acudir desde Cádiz a Cataluña era la navegación marítima, pero, sin embargo y por este motivo, Valdés fue obligado a hacer otra ruta más acorde con las intenciones de la Armada. Se le mandó seguir un trayecto determinado, ejecutándolo con visos de exhaustividad y

52 AGS, Secretaría de Marina, 553. Recibido en La Carraca el 6 de agosto de 1738. Documento emitido por Juan Valdés y Castro, «Capitán de Fragata y teniente de dicha Capitanía de Maestranza», en compañía de Juan Pinzón, capataz de arboladura.

53 Fernández Duro, 1972-1973, 319.

54 AGS, Secretaría de Marina, 553, Cádiz, 30 de octubre de 1738. 
no efectuándolo por mar, sino transitando obligatoriamente por ciertas zonas maderables del interior peninsular que le compelía a dar rodeos por áreas boscosas del interior castellano, aragonés y catalán indicadas de manera expresa. Además, le fue ordenado que no se centrase exclusivamente en zonas boscosas de realengo, sino que también reconociese montes particulares, de propios y comunales.

En 1739, tras haber realizado los trabajos encomendados, el militar compiló todos su informes en lo que él mismo denominó como «Diario, especulación y conocimiento hecho por el Capitán de Fragata Dn. Juan de Valdés y Castro en el Principado de Cataluña, Reyno de Aragón, y de Navarra de los Ríos, Riveras Fabricas de Jarcia, Alquitranes Betunes Arboles, y cosechas de Cáñamos de cada Pueblo». ${ }^{55}$ Se trata de un minucioso manuscrito de 34 páginas que, además de estar poblado de datos geográficos, técnicos, medidas, cifras y detalles, recoge una serie de comentarios relativos a aspectos jurídicos a los que él parece prestar un valor secundario, pero que son de gran valor de cara a dilucidar las posibles intenciones de la Armada sobre las cuestiones de propiedad para el abastecimiento maderero. Así, Valdés reconoció que siguió las órdenes encomendadas y no sólo visitó montes pertenecientes a la Corona, sino que centró buena parte de sus actividades en recorrer y anotar la utilidad para la Marina de terrenos privados, vecinales o eclesiásticos.

Además del diario, Valdés emitió un informe en el que hablaba de la necesidad de compensar las cortas de árboles ubicados en terrenos particulares mediante el pago a sus propietarios de una cantidad que debería ser justa, así como la necesidad de abrir caminos hasta los ríos navegables. Éste último es un aspecto que pareció preocuparle especialmente ya que en sus escritos incidió mucho sobre el resarcimiento por los perjuicios que se causarían a los propietarios por las talas que haría la Marina. ${ }^{56}$

Junto a todos estos pormenores, hubo otro asunto que era igualmente importante para lograr el resultado deseado. Coetáneamente, Antonio Gallego de Montemayor, quien había acompañado a Valdés en su viaje, emitió otro informe adjunto a éste en el que manifestaba que había estado intentando inculcar a los naturales de la necesidad de compatibilizar sus prácticas forestales consuetudinarias con las necesidades del real servicio

55 AGS, Secretaría de Marina, 553, Diario de Juan Valdés y Castro, 1739. Fernández Duro, 1972-1973, 319.

56 AGS, Secretaría de Marina, 553, Informe de Juan Valdés y Castro, 1739. 
naval, lo que frecuentemente era origen de los choques entre las necesidades marítimas y los intereses locales. Gallego apuntó que estos conflictos los había descubierto sobre todo recorriendo «los Bosques de las inmediaciones de los Ríos Nogueras, y Segra». En ellos advirtió abusos en los montes por parte de los vecinos, por lo que se planteó «educarlos» [sic] para compaginar sus carencias con los requerimientos de la Monarquía. Pero, del mismo modo que se quejó de las maneras de actuar por parte de la población local, también se lamentó por no disponer de una norma que regulase el asunto y que suponía que, al no existir, sus esfuerzos podrían llegar a ser infructuosos. De tal modo que si no se ponía remedio prontamente «resultará en la continuación la total destrucción de aquellos bosques». Por ello, informó:

\begin{abstract}
de lo conveniente que se consideraba se prefijasen reglas para su conservación, estableciendo las formalidades con que los Dueños y Comunes deben usar de los Palos que necesiten para servicio de sus fabricas, y beneficiar â los Particulares, y Lugares circunvecinos que los necesitasen para precaver que los que se han dado por aptos para Arboladuras de Bajeles no los corten y permanezcan para los efectos que el Rey los necesite; Y no habiendo recibido hasta ahora orden alguna sobre este asunto que prescriba la norma que debe seguirse en lo sucesivo para la conservación de ellos, Y teniendo noticia que los Dueños de los Bosques continúan los cortes de Arboles sin reflexión â los perjuicios del Real Servicio que ocasionan abatiendo los mayores, por tenerles menos coste, y sacan más beneficio. ${ }^{57}$
\end{abstract}

Finalmente, al margen de estos terrenos explorados, Pascual Madoz referirá un siglo más tarde que, desde 1739, también vinieron efectuándose inspecciones en Cantabria. Según él, fue nombrada una comisión que encontró mucha más madera de la que se pensaba que existía, como para construir entre 16 y 20 navíos de línea. Inmediatamente se designó a Ciprián Autrán para pasar a Guarnizo y supervisar las cortas que abastecieran a los arsenales «quedando pequeña cantidad en el país»..$^{88}$

\title{
Últimas actuaciones previas a la Ordenanza
}

Por otro lado, José Campillo y Cossío, anteriormente citado, accedió al frente de la Secretaría de Marina en 1741. Su actividad se centró más en

57 AGS, Secretaría de Marina, 553, Informe de Antonio Gallego, 1739.

58 Madoz, 1847, 50. 
los aspectos teóricos, abogando por la importancia de impulsar la Marina. ${ }^{59}$ En dos de sus obras afrontó las imperfecciones hispánicas así como las medidas que consideraba más útiles para su remedio. Sus escritos pueden considerarse como característicos del mercantilismo de la primera mitad del siglo XVIII, con enormes influencias de Colbert. ${ }^{60}$ Será una constante su queja por la falta de efectivos navales, opinando desde su experiencia personal que «la importancia de los navíos de línea es tan grande que se puede decir que mientras mayor sea el número de ellos, tiene el príncipe más bien amurallado su reino». ${ }^{61}$ Consecuentemente, aportó también su opinión sobre la necesidad de preservar las masas forestales:

los navíos todos son compuestos de madera y, siendo esto así, ¿cómo ha de haber navíos careciendo de árboles? No se dice que no se hayan dado repetidísimas reales providencias contra los taladores de ellos, pero si el castigo de los delincuentes no ejemplariza, y si no se pone en que se guarden ni aún el material cuidado que se emplea cuando se escriben, ¿es esto más que imponer precepto tan al aire como que se deja al común arbitrio su observancia? ${ }^{62}$

Completando esta denuncia, ponía el dedo en la llaga evidenciando la ineficacia de las disposiciones forestales que habían venido empleándose hasta entonces y haciendo espacial hincapié en la necesidad de elaborar nuevos instrumentos normativos:

es necesario tome el gobierno otras providencias distintas de las que hasta aquí ha usado para la subsistencia de árboles y plantíos, pues si esto falta para la construcción de los barcos no importa nada haya dinero de sobra. ${ }^{63}$

Poco después, en 1743, fue Ensenada quien se erigió al frente de la Secretaría de Marina. Pronto se prestó a continuar con el proyecto de creación de una fuerza naval poderosa, como arma indispensable para el resurgimiento de España como potencia, procurando sostener una postura neutral en un contexto que, a pesar de los episodios militares, pasaba por desarrollar una política de paz armada manteniéndose equidistante entre

59 Perona Tomás, 1999, 139.

60 Mateos Dorado, 1993, LXX.

61 Ibidem, 218-219, «España despierta» (texto comenzado el 27 de febrero de 1742).

62 Ibidem, 113, «Lo que hay de más y de menos en España, para que sea lo que debe ser y no lo que es» ( 8 de agosto de 1741-18 de febrero de 1742).

63 Ibidem, 218, «España despierta». 
Francia e Inglaterra, ${ }^{64}$ así como recuperar el control económico de las Indias ${ }^{65}$ para poder operar en las rutas trasatlánticas con los territorios americanos. ${ }^{66}$ La situación apremiaba sobre todo debido a que, ante frecuentes ataques ingleses, la navegación por el océano tenía que reforzarse con buques de Francia puesto que la Marina de guerra española aún no podía hacer frente a la británica: ${ }^{67}$

A pesar de los anteriores esfuerzos de Patiño, cuando Zenón Somodevilla accedió al cargo la situación naval era precaria. Como se expuso, desde 1739 la monarquía hispánica se encontraba inmersa en la Guerra de la Oreja de Jenkins o Guerra del Asiento, que tendría repercusiones en su política naval y mercantil. ${ }^{68}$ Ensenada se apresuró a enviar órdenes para reforzar las defensas y aumentar la fabricación de navíos de guerra. En este escenario y a pesar de los esfuerzos, se llegarán a perder casi una cincuentena de barcos y reducir sus efectivos a límites alarmantes hasta sólo «18 navíos y 15 embarcaciones menores». ${ }^{69}$ Así las cosas, España no podía erigirse como una potencia superior a Francia o Inglaterra y la opinión de los consejeros reales era que debía aspirar a convertirse en un elemento de equilibrio en la política europea. ${ }^{70}$ Ello pasaba obligatoriamente por incrementar la explotación forestal.

No obstante, a pesar de su decisión de hacer resurgir la Marina, Ensenada no expuso al principio con claridad y precisión el conjunto de sus proyectos jurídicos y técnicos sobre el abastecimiento de maderas y esta primera falta de concreción sería dañina para unos montes que terminarán viendo cómo se rectificaban, rehacían y ampliaban frecuentemente diversas disposiciones tomadas. ${ }^{71}$ Estas improvisaciones eran perniciosas por la propia naturaleza de los montes, dado que en caso de efectuar cortas, si estaban mal hechas no podía volver a rectificarse hasta décadas después y el abastecimiento de maderas sólo podría llevarse a cabo mediante la ampliación de las zonas de tala.

64 «El que quiera conseguir la paz es de común axioma que ha de preparar la guerra». Esta expresión de Zenón Somodevilla es citada en Abad León (1985, 156), tomada a su vez del documento, transcrito por Rodríguez Villa, titulado Idea de lo que parece preciso en el día para la dirección de lo que corresponde al Estado y se halla pendiente.

65 Ibáñez de Ibero, 1949.

66 Díaz Ordóñez, 2009, 135-136.

67 Ruiz Torres, 2008, 197-198.

68 Franco Castañón, 2009, 237.

69 Serrano Álvarez, 2002, 28. Salas, 1865, 165-169.

70 Díaz Ordóñez, 2009, 169.

71 Merino Navarro, 1981, 192. 
Lo que sí es cierto es que, traspasado el primer tercio del siglo, la actividad de la Armada por fin dejaba realmente entrever que estaba trabajando para dotarse de un nuevo instrumento normativo para controlar los montes y llevar a cabo una política de repoblación forestal con la que asegurarse el abastecimiento de maderas. Ello se infiere de la abundante correspondencia mantenida entre la Secretaría de Marina y los diversos comisionados que se dirigían a ella solicitándole disposiciones a las que poderse atener para evitar problemas en las extracciones de madera. Basten tres ejemplos de diferentes latitudes:

a) Desde la Secretaría de Marina se pidió en 1743 al Departamento de El Ferrol que averiguase si allí se habían dotado de alguna norma en tiempos pasados que pudiese ser útil para la elaboración de una Ordenanza de Montes. Su intendente, Bernardino Freyre, contestó afirmativamente diciendo que habían hallado una instrucción forestal de 1675. Marina pidió que le fuera remitida con urgencia para poder estudiarla:

Teniendo noticia de que todos los papeles tocantes al Juzgado de Montes de ese Reyno los mando VS entregar en la Contaduría del Departamento de Marina de ese Puerto por haber resuelto S.M. agregar al empleo de VS. el referido Juzgado y hallarse, al mismo tiempo, entre ellos, la instrucción, que se expidió en 19 de mayo de 1675 , sobre lo que se debía observar en la conservación, y aumento de los referidos Montes; ha acordado el Consejo, que respecto de necesitarse el tenerse presente la expresada Instrucción, disponga VS. sacar copia de ella, y remitírmela Certificada, con la mayor brevedad, que fuere posible; de que participo a VS. para su inteligencia, y cumplimiento. ${ }^{72}$

b) Por otro lado, ante una serie de disputas con la ciudad de Sanlúcar la Mayor, sita en la provincia marítima de Sevilla, el intendente que también fue del Departamento de Cádiz, Alejo Gutiérrez de Rubalcaba expresó su malestar porque el Consejo había conferido permiso a la población «para limpiar, arrancar, y entre sacar el Monte bajo, de la Dehesa del Campillo». Sin embargo, la respuesta de Marina consistió en emplazar al intendente a esperar la llegada de una norma que se estimaba erradicaría aquel tipo de conflictos:

deje correr el Despacho del Consejo; pues luego se publicará la Ordenanza de Montes, y Plantíos con lo qual cesarán las disputas semejantes â esta, que hasta ahora se han experimentado. ${ }^{73}$

72 AMN, Ms. 2137-4, El marqués de Ustáriz a Bernardino Freyre de Moscoso, Madrid, 1 de mayo de 1743 .

73 AGS, Secretaría de Marina, 554, Madrid, 4 de abril de 1747. 
c) En el extremo opuesto de la Península, el 23 de abril de 1744, Juan de Rebollar se quejó a Ensenada de la falta de colaboración de las instituciones locales cantábricas con la Marina, solicitando instrucciones para actuar en consecuencia. La respuesta llegó en pocos días —el 4 de mayoy es tan significativa como la dirigida al Departamento gaditano:

Que brevemente se publicara la Ordenanza sobre Montes, y Plantíos, y que entre tanto aplique las providencias, que considere correspondientes a remediar el daño de las cortas indebidas, avisando que sujetos lo hacen, para que se proceda a su castigo. ${ }^{74}$

A estas actuaciones se le añadió otra visita general en 1745 hecha por oficiales de la Marina a todos los bosques útiles próximos a las costas para valorar cómo se encontraban. Fueron levantados planos de las áreas visitadas y se clasificaron diferentes tipos de piezas para la construcción de navíos. Se remitieron órdenes a los tres Departamentos para que enviasen a la Secretaría de Marina los resultados de las inspecciones. Los planos forestales que se trazaron recogían aspectos de singular relevancia que serán tenidos en cuenta por la futura Ordenanza forestal tales como la propiedad, ubicación y delimitación geográfica de los bosques, sus especies arbóreas, un inventario de las mismas y la distancia de los montes respecto de la costa o ríos navegables o posibles nuevas vías de acceso. ${ }^{75}$

\section{La Ordenanza de Montes de Marina, de 31 de enero de 1748}

Como se ha advertido, la administración borbónica era consciente de la crítica situación naval y, sobre todo, conocía la decisiva importancia de los recursos forestales para la política económica y militar de la Monarquía. ${ }^{76}$ El resultado de los trabajos previos que se acaban de citar tuvo finalmente su plasmación escrita una Real Ordenanza para los montes destinados al servicio de la Marina. Bajo el nombre de Ordenanza que su Majestad, (Dios le guarde) manda observar para la Cría, Conservación, Plantíos y Corta de los Montes, con especialidad los que están inmediatos a la Mar, y Ríos Navegables. Método, y Reglas que en esta materia deben seguir los Intendentes de Marina, establecidos en los tres Departamentos

74 AGS, Secretaría de Marina, 554, Correspondencia mantenida entre Ensenada y el astillero de Guarnizo, 4 de mayo de 1744.

75 Aranda y Antón, 1990, 21, 43 y 49.

76 Urteaga, 1987, 127. 
de Cádiz, Ferrol y Cartagena, fue promulgada por Fernando VI en el Buen Retiro, con fecha de 31 de enero de 1748, siendo consecuencia de la política de un Zenón Somodevilla obsesionado por el dominio del océano. ${ }^{77}$ Éste aspecto fue presentado en el preámbulo de la norma como fundamentales para obtener el bien común del reino, «de la qual se sigue tanta utilidad à mi servicio, y a mis vasallos». Portillo Valdés apunta que, efectivamente, a nivel interno la disposición respondía al espíritu que animó a los proyectos de Ensenada, en los que jugó un papel clave el desarrollo de la policía «abandonada y descuidada enteramente en los pueblos de España». ${ }^{78}$

En su conjunto, estas disposiciones conformaban un compendio de legislación forestal que sistematizaba concienzudamente no sólo la política de plantíos, sino también la administración y gobierno de los montes. Tal gestión partía de una concepción utilitarista de los mismos, sólo concibiendo a los bosques como espacios susceptibles de producir materiales estratégicos para la construcción naval. ${ }^{79}$ Precisamente por eso, poco después Ensenada escribiría en una representación a Fernando VI que «lo que por economía y por política conviene presentemente es cortar, labrar y curar maderas y preparar herrajes para la construcción de buques». ${ }^{80}$

Esta Ordenanza se justificaba a sí misma aludiendo al decadente estado de los bosques. La norma se dirigía a distritos y provincias concretos, en los que debía ser ejecutada, sin tener en cuenta la existencia de privilegios, derechos, y costumbres,$^{81}$ abarcando múltiples aspectos con objeto de dejar tasado todo el organigrama, el procedimiento de plantaciones y cuidado de ejemplares, así como el fomento de árboles para mantener permanentemente abastecidos de troncos y tablazón los arsenales de la monarquía.

\section{Intendentes, ministros y visitas de reconocimiento}

El cuidado de los montes próximos a la costa y a los cursos de los ríos navegables continuaba a cargo de los intendentes de Marina establecidos en

77 Ordenanza, que Su Majestad, (Dios le Guarde) manda observar para la cría, conservación, plantíos y Corta de los Montes, con especialidad de los que están inmediatos a la Mar, y Ríos Navegables. Método, y reglas que en esta materia deben seguir los intendentes de Marina, establecidos en los tres Departamentos de Cádiz, Ferrol y Cartagena. Ejemplar empleado del AMN F006-41. También recogido en Novísima Recopilación; Lib. VII, Tít. XXIV, Ley XXII.- Abad León, 1985, 225-228. Urteaga, 1987, 128.

78 Portillo Valdés, 1981, 413. Cita a Abad León, 1985, 190.

79 Urteaga, 1987, 128.

80 Abad León, 1985, 8. Cita misiva fechada en Aranjuez, 28 de de mayo de 1748.

81 Gibert y Sánchez de la Vega, 1971, 323. 
cada uno de los Departamentos, con jurisdicción ejercida por sí mismos o por sus delegados, debiendo inhibirse todos los demás juzgadores y asumiendo por tanto la competencia correspondiente a los jueces de montes y provincias marítimas (art. 1).

Aquellos intendentes debían ordenar a los ministros de Marina, establecidos en los principales puertos, la tarea de llevar a cabo una visita de montes mediante la que redactar una relación o memoria sobre los bosques y su estado, diferenciando entre los realengos y los que pertenecieran a particulares, y de los pueblos, comunes y propios.

Sobre los ejemplares inspeccionados, se ordenaba que la relación fuese meticulosa, incidiendo en determinadas especies útiles para el real servicio: «expresando su latitud, situación y el número de árboles que tengan en pie, así robles como encinas, carrascas, alcornoques, álamos negros y blancos, chopos, fresnos, alisos, nogales, hayas, castaños y pinos, dividiéndolos en clases según la calidad, y distinguiendo su edad con la nota de nuevos, crecidos y viejos» (art. 2). Los ministros en cada visita debían tener en cuenta, no sólo los montes ya existentes al servicio de la Marina, sino también las posibilidades de extender su radio de acción a otras masas forestales, expresando datos de utilidad tales como el número de «baldíos, su extensión y calidad, distancia de la costa, facilidad o dificultad de abrir carriles hacia ella, y que especies de árboles prevalecerán mejor en cada uno» (art. 3).

La Ordenanza también se ocupaba de los posibles conflictos de jurisdicción con los que se pudieran encontrar los visitadores durante sus inspecciones. Así en su artículo 4, exponía: ${ }^{82}$

Como la Justificación de la verdadera extensión, o capacidad de cada Monte podría detener esta diligencia en aquellos Lugares que tienen o pretenden tener derecho a Montes, o partes de ellos, en cuya posesión estén otros Lugares, o Particulares: Mando, que los referidos Instrumentos se formen, según lo que cada Lugar esté actualmente poseyendo; entendiendo, sin embargo, los Visitadores a las pruebas con que las Partes justifiquen sus pretensiones, y oyendo a los Vecinos de mayor inteligencia de los Lugares, mediante cuyas diligencias puedan amojonar, y calcular los términos, y divisiones, quedando no obstante a cada uno su derecho salvo.

Dichas visitas no devengaban ningún tipo de salario o gratificación a favor del ministro, ni por parte de Marina, ni a cuenta de los pueblos recorridos (art. 39). En cuanto al modo de llevarlas a cabo, se obligaba a que el ministro de cada provincia llevase alguacil y escribano, debiendo anotar los

82 Ibidem, 324. 
autos y diligencias del visitador en un registro (art. 40). Estos oficiales percibirían su salario de las multas impuestas a aquellas Justicias y vecinos sancionados por haber incumplido los mandatos establecidos en la Ordenanza, a saber: no haber hecho viveros, o no plantar los ejemplares establecidos por esta norma, no haber evitado el descortezo, averiguado o perseguido los incendios, no haber concurrido a apagarlos, haber cortado árboles sin licencia y otras contravenciones «que se noten en la policía y buen gobierno de esta materia tan importante a mi servicio y al bien de mis Reinos» (art. 41).

En conclusión, el objetivo era claro. Todas las tareas de cuidado, vigilancia, reconocimiento, economía y gobierno forestales, es decir, todo lo que podía ser cometido de una policía de montes quedaba sometido a los nuevos intendentes borbónicos y sus ministros. ${ }^{83}$

\section{Obligación vecinal de plantar}

En los montes que quedaban sujetos a la jurisdicción de Marina, cada vecino estaba obligado a plantar al menos tres árboles de la especie indicada por el visitador. Sobre esta obligación no se eximía a los nobles ni a los matriculados en la Marina, entendiendo que si la utilidad de los plantíos era común, también debía serlo la concurrencia a ellos. Al respecto, únicamente eran exonerados de esta carga las viudas pobres y sin hijos mayores de dieciocho años o los vecinos «notoriamente imposibilitados». Para estar al corriente de a quienes correspondía esta obligación en cada población se requería la ayuda de las Justicias locales (art. 5).

\section{Construcción, cuidado de los viveros, trasplante y crecimiento de ejemplares}

La Ordenanza recogía una serie de instrucciones técnicas sobre el nacimiento y cría de los árboles, contempladas entre los artículos 7 y 15. Así respecto a los viveros, establecía que la ubicación de éstos se debía efectuar teniendo en cuenta que hubiere suficiente espacio, los ejemplares estuviesen descubiertos del sol y protegidos de los vientos del norte, plantándose las bellotas más gruesas y sanas procedentes de los robles más

83 Portillo Valdés, 1981, 485. 
robustos. El terreno destinado a vivero debería ser labrado entre los meses de septiembre y enero mediante la apertura de pequeños surcos y la colocación manual de las bellotas, quedando prohibida la entrada de ganado u otro tipo de animales que pudiesen destruir las plantas incipientes (art. 7).

A los tres años siguientes se obligaba a efectuar limpias de malezas y arranques de otras plantas que pudieran menoscabar el crecimiento del árbol. Además, con el fin de enriquecer el suelo, se hacía preceptivo añadir estiércol, (art. 8). En cuanto a la plantación, cuando el joven árbol hubiese alcanzado un «grueso de tres pulgadas y media a cuatro de circunferencia» debería ser plantado fuera del vivero (art. 9) ${ }^{84}$ Antes de efectuar esta operación, durante los tres primeros años de vida del árbol, éste había de ser podado en ciertas ramas, dejando solamente las conocidas como guías. Para llevar a cabo el cambio de terreno del ejemplar era obligatorio seguir diversos criterios (arts. 9 a 14) que hacían referencia al lugar, momento, modo distancias entre árboles, trabajos en la tierra, prevención de destrozos por el ganado y criba de ejemplares.

Finalmente, al referirse al crecimiento de los árboles, la Ordenanza encomendaba su vigilancia a contramaestres y expertos en construcción naval, a cuyas necesidades y requerimientos se debía ajustar el cultivo para obtener las piezas necesarias en la fabricación de los buques. Con este fin la norma mandaba «que todos los árboles nuevos crezcan y se guíen con la vuelta o tortura natural que tengan; dándosela mayor, si les pareciere conveniente, por medio de alguna ligera artificiosa disposición, para que, creciendo así, puedan sin violencia formar a su tiempo en la construcción de los bajeles el miembro que les convenga». Este precepto permite entrever que la última ratio de la Ordenanza no era la preservación y fomento de la foresta per se, sino la obtención de materias primas que resultasen útiles para la construcción naval.

\section{Podas y guías (arts. 16 a 20)}

Entre los menguantes de las lunas de noviembre a febrero debían llevarse a cabo las podas, siguiendo la creencia extendida de evitar que el

84 El Diccionario de la Real Academia Española entiende por «pulgada» la «medida que es la duodécima parte del pie y equivale a algo más de $23 \mathrm{~mm}$ ». Tomando esta dimensión como base ha de pensarse que el momento del trasplante debía producirse cuando el tronco del ejemplar hubiera alcanzado entre 80,5 y 92 milímetros de circunferencia. 
agua proveniente de los efectos humidificadores de la luna no dañase a los árboles al entrar ésta entre la corteza y el tronco, lo que se estimaba era perjudicial para la salud de la madera (art. 16). Esta cuestión tenía importantes repercusiones a efectos prácticos puesto que, al establecerse como criterio las fases lunares, si no se podaba o talaba de acuerdo con cada período había que retrasar bastantes meses la provisión de materias primas para la fábrica de navíos hasta que de nuevo fuera posible cercenar los árboles, en el menguante de noviembre. ${ }^{85}$

Todas estas podas debían hacerse siguiendo criterios técnicos consistentes en dejar horca, guía y pendón o pica de las ramas más robustas, buscando las figuras más óptimas, «proporcionadas», para la arquitectura naval como piezas de construcción ${ }^{86}$ para lo cual los intendentes deberían disponer de podadores expertos en la fábrica de bajeles y eran quienes indicaban dónde debían efectuarse las talas de los ejemplares (art. 17). Gracias a estos trabajos silvícolas se obtendrían piezas aptas para la elaboración de elementos marineros tales como baos, quillas, sobrequillas, codastes, yugos o tablazón (art. 18).

A este respecto, se exigía que los procedimientos de corta fuesen únicamente los expresados, de tal modo que si se cercenaban árboles indebidamente y éstos dejaban de ser útiles para el Real Servicio, deberían ser castigados los contraventores «rigurosamente». La custodia que evitase estas podas ilícitas correspondía a las Justicias y en caso de no dar con el autor de los excesos incurrirían ellas en responsabilidad (art. 19), sin precisar en qué consistiría tal responsabilidad.

85 Lo cierto es que esta práctica era usual a la hora de extraer la madera. Así, por ejemplo, años antes de la publicación de la Ordenanza, el 28 de mayo 1739, un comisionado de Marina, Manuel García Gómez, se dirigió a Ensenada desde Guarnizo, en Cantabria, haciéndole ver que cumplía con el criterio de las fases lunares al comentarle que las plantaciones de los árboles debían realizarse «durante la creciente, y que en la menguante siguiente concluiría la corta de toda la madera que se necesite en El Ferrol». AGS, Secretaría de Marina, 553.

86 En un tratado de la década anterior se describía como horca y pendón «dejar una buena rama hacia un lado en ángulo recto con el tronco, o otra derecha, o en ángulo obtuso, para que tengan curvatones, genoles, o barengas para Navíos» (Bernardo, 1736, 160). Dentro de una de las acepciones del vocablo «horca», el Diccionario de Autoridades de 1737 recoge la expresión Dejar horca y pendón, entendiendo por la misma «Frase de las leyes y ordenanzas sobre la corta de los montes, con que se manda que en los arboles mayores se deje el tronco con dos ramas, para que en ellas vuelva à formarse el árbol: y en el que llaman Monte bajo la guía ò vástago principal, para que se críen nuevos árboles». Por su parte el mismo diccionario en su edición de 1734, entiende por guía, entre otras, «el sarmiento que se deja en la cepa para que dé el fruto». 


\section{Leñas (arts. 21 a 25)}

Las leñas producidas a causa del aprovechamiento de los árboles mediante las cortas y podas de la Marina en los montes concejiles o comunes, o de realengo se repartirían entre los vecinos de los pueblos proporcionalmente, en función de la familia y consumo de cada uno. A falta de ramaje se permitía el corte de leña procedente del monte bajo (art. 21). La leña sobrante sería objeto de venta, preferentemente a favor de los asentistas de artillería u otros pertrechos al servicio de la Corona (art. 22). En caso de que los lugares pretendiesen establecer precios desorbitados, los intendentes o sus comisionados en cada partido estaban facultados para moderarlos y a estos mismos les correspondía ordenar las podas, con el fin de que la actividad de las fábricas y herrerías no se paralizasen por falta de suministro de combustible (arts. 23 y 24). El caudal producto de la venta de las leñas debería ser depositado con destino al aumento de los plantíos comunes y al pago de tributos, censos, gravámenes y obras públicas que no pudiesen ser sufragados por propios o arbitrios, todo ello bajo la dirección del ministro de Marina de la jurisdicción correspondiente (art. 25).

\section{Otros aprovechamientos y beneficios}

Además de la leña, las poblaciones rurales se habían abastecido tradicionalmente de otros recursos provenientes de las masas forestales. También sobre dichas prácticas de aprovechamiento la nueva norma pretendió ocuparse, regulando su explotación. Así, las bellotas y las hojas de «los arboles nacidos comunes y Realengos» debían ser distribuidas entre los vecinos, sin gravamen ni contribución, «aunque las dehesas me pertenezcan en propiedad [del rey]». En este sentido, la Ordenanza de Montes de Marina pretendía teóricamente guardar las constituciones, reglas y costumbres de los lugares siempre que no establecieran distinciones entre los vecinos (art. 26). ${ }^{87}$

Con la intención de mostrar a los pueblos el interés del Real Servicio en la cría y el aumento de árboles, la disposición mandaba a los intendentes de Marina abonarles un real de vellón por cada codo cúbico de madera

87 Este art. 26 sería contravenido sistemáticamente en el caso de la Sierra de Segura ya que el Ministro del lugar no permitió esos aprovechamientos a pesar de la indigencia de la población y sus ganados. Vid. en AGS, Secretaría de Marina, el enorme legajo n. ${ }^{\circ}$ 576, dedicado de modo expreso a los conflictos jurisdiccionales de la zona. 
de roble que se extrajese limpiamente para la Armada (artículo 27). ${ }^{88}$ Este es el mismo precio que debía ser pagado a los particulares y las poblaciones por los asentistas que proveyeran a los arsenales y astilleros. Sin embargo la misma cuantía no se aplicaba para aquellos casos en los que quienes cortasen los árboles fuesen particulares con licencia para construir naves, ya que ellos deberían pagar el doble por cada codo cúbico (art. 28). Todos estos taladores estaban obligados a permitir que las ramas y leñas menudas sobrantes pudieran ser aprovechadas por los pueblos.

\section{Montes de particulares}

Los montes pertenecientes a particulares también se encontraban sujetos a la prohibición de cortar árboles propios libremente. ${ }^{89}$ Para poder hacerlo se requería comunicarlo a los intendentes o subdelegados de Marina y obtener su permiso. Previamente, los visitadores deberían haber marcado los árboles útiles para el Real Servicio en las visitas, y en caso de que los ejemplares solicitados por los particulares tuviesen dicha marca, los peticionarios tendrían la obligación de restituirlos con nuevos árboles. Ahora bien, en el supuesto de que la Marina necesitase de estos montes particulares, sus dueños tendrían preferencia para tomar asiento o contrata en la conducción de las maderas a los arsenales o astilleros. En caso de no aceptar esta propuesta se les abonarían los precios establecidos por la Ordenanza para la adquisición de maderas por cuenta del rey o por cuenta del asentista que actuase. Respecto a los particulares que hubiesen obtenido permiso para cortas en estos terrenos privados, el precio se convendría libremente entre éstos y los dueños. Los propietarios tenían la facultad de retener los beneficios de las podas, así como emplear los árboles inútiles para la construcción de bajeles, pero a su vez quedaban obligados a cuidar los montes siguiendo las reglas de la Ordenanza (art. 33).

$881 \mathrm{codo}^{3}=323 \mathrm{dm}^{3}$. Cálculos efectuados por Gibert, 1971, 325 .

89 Existían precedentes inmediatos de esta restricción sobre la libre disponibilidad de la madera en terrenos particulares. Como ejemplo, el 3 de marzo de 1745, desde Avilés, José de Colosia solicitó a Ensenada que se le concediera la «facultad para poder dar licencias que le pidan los vecinos de los Pueblos de aquel Principado para que corten los Arboles para reparo y fábricas de casas [...] en sus propios montes sin tocar en los comunes, ni Plantíos». Sin embargo, el 17 de marzo de 1745 se contestó permitiéndole otorgar los permisos, pero de modo restrictivo al tener el fomento de las arboledas como última ratio la fabricación de embarcaciones: «encargo a V.m. que estas cortas se hagan en Montes de particulares, cuidando al mismo tiempo que los Arboles que se derriben no sean a propósito para la construcción de Navíos». AGS, Secretaría de Marina, 554. 


\section{Licencias de cortas}

La Ordenanza entendía que prohibir absolutamente la corta de árboles por parte de los particulares que vivían en las zonas de jurisdicción de la Marina podía serles perjudicial. Por este motivo se habilitaba a los subdelegados para permitir la corta de árboles necesarios mediante solicitud escrita del particular o comunidad, declarando la porción de madera y su finalidad. La petición era enviada a la Justicia local correspondiente, quien debía informar ratificando si los datos de la pretensión eran ciertos, la cantidad de madera que la obra del particular precisaría, así como concretar el paraje en donde se podía llevar a efecto la corta, exceptuando siempre los lugares próximos a los embarcaderos puesto que éstos se encontraban en exclusiva destinados al Real Servicio (art. 31)..$^{90}$ En caso de que en el lugar solicitado no existiese la madera precisa, el subdelegado podía permitir su corta en el término de otra jurisdicción, mediante remisión de la instancia a la Justicia de la nueva demarcación (art. 32). Correspondía a los subdelegados otorgar las licencias para las cortas, tras el previo informe de la Justicia o «de otros de quienes hubieren tenido por conveniente informarse». En caso de que la licencia fuese efectivamente concedida debían ser conservadas por los justicias o los dueños de los montes, con objeto de poder justificar las cortas (art. 34). Estos controles se completaban con una exhaustiva contabilidad plasmada en un libro abierto, llevado con las garantías propias de un registro, en el que era obligado reflejar los árboles presentes, plantados y cortados (arts. 35 y 36). Los ministros de las provincias marítimas debían llevar libros similares remitiendo copias de los mismos a los Departamentos e intendentes y, a su vez, éstos estaban obligados a remitir copia al Secretario de Despacho de Marina (art. 37).

\section{Multas, salarios y su cobranza}

La multas no podían ser objeto de indulto, pero con anterioridad a ser ejecutivas se remitían para su aprobación al secretario de Despacho de Marina con el fin de que «antes de imponerlas, se examinarán con mucha

90 El artículo 31 de la Ordenanza fue un intento de sistematizar procedimientos y criterios a tener en cuenta en el momento de solicitar y otorgar licencias para talas por parte de particulares. En ellas, los solicitantes debían exponer que la madera pedida se utilizaría para asuntos domésticos. Sin embargo, los requerimientos de obtener madera para el real servicio pesaban más que las necesidades de los vecinos: los ejemplos en el siglo XVIII contenidos en el AGS, Secretaria de Marina, 552, son múltiples, y afectaban incluso al estamento nobiliario. 
reflexión, y se justificarán las razones en que se funden» (art. 42). Del caudal obtenido por estas sanciones pecuniarias se señalaban los salarios concernientes los alguaciles y escribanos. El resto del caudal debía ser remitido a la Tesorería de Marina. En caso de que la cantidad percibida por la cobranza de multas no alcanzase la cuantía suficiente para hacer frente a los salarios de los oficiales se sufragarían de la Real Hacienda puesto que la norma obligaba a que en ningún caso se soslayasen las visitas bianuales (arts. 43 y 44).

El modo de proceder de los visitadores tenía que ser «sumariamente conforme a Derecho, prescindiendo a los reos, tomando las confesiones de sus delitos, y recibiendo, si fueran graves, la causa a prueba con término competente y breve, cual conviene para justificación de causas locales, sentenciándolas con parecer de Asesor». En el caso de interponerse apelación ésta debería presentarse ante el intendente del Departamento, y posteriormente cabría recurso frente al secretario de Despacho (art. 45).

De la cobranza de las cantidades abonadas en concepto de multa se encargarían las justicias ordinarias de cada lugar, no debiendo esperar los visitadores a percibirlas puesto que su obligación era la de continuar la visita lo más rápida y eficientemente posible (art. 46).

En el caso de que se requiriese un mayor número de auxiliares que se ocuparan de las labores de guardería de montes, serían nombrados por el ministro de la provincia marítima, de acuerdo con la Justicia del lugar, o por el subdelegado con la aquiescencia del ministro. Los salarios de estos guardas celadores de montes debían ser satisfechos siguiendo el mismo procedimiento de cobranza de multas. En su cometido, las Justicias estaban obligadas a «darles todo el favor y auxilio que necesitaren para custodia de dichos montes, y evitar las talas y quemas, aprehendiendo a los agresores».

\section{Comercio y transporte de maderas}

Incluso aunque hubiera madera que no fuese a emplearse en la fábrica de navíos, se consideraba ilícita su extracción para ser vendida a «dominios extranjeros» si no mediaba orden expresa del rey. Esta prohibición no sólo se centraba en la madera del roble sino también en cualquier otra, aunque fuese poco codiciada en la arquitectura naval (art. 49). Respecto al transporte marítimo de troncos, tablones y otras piezas maderables destinadas a los astilleros, los asentistas deberían llevar guía del comisario o subdelegado de Marina del puerto en donde se embarcase, recogiendo el 
número y calidad de las maderas cargadas. Asimismo se le exigía traer «certificación o vuelta de guía del Contador del astillero o arsenal donde se desembarcaren visada del Intendente».

\section{Disposiciones específicas para cada uno de los Departamentos, de Cádiz, El Ferrol y Cartagena}

Los artículos 52 a 79 enumeraban detalladamente todas y cada una de las jurisdicciones de las provincias marítimas que pasaban a depender de cada uno de los tres grandes Departamentos en los que, como ya se ha visto, el intendente se erigía como la máxima autoridad encargada del gobierno y administración forestal. Los ministros de Marina actuaban como sus delegados en cada una de las provincias que conformaban cada Departamento. El reparto de competencias y zonas boscosas para los respectivos Departamentos marítimos fue diseñado por la Ordenanza adoptando providencias diversas en función de las características propias de cada una de las heterogéneas regiones que abarcaban para optimizar la gestión y explotación de los recursos.

\section{Conclusiones}

Mediante el presente análisis hemos pretendido demostrar cómo los aspectos forestales, dentro del contexto de la política naval, constituyeron un asunto que influyó de forma sobresaliente en el devenir histórico hispánico frente a otras potencias de nuestro ámbito. La estrategia política precisaba de todo un conjunto de medidas tendentes a impulsar el mayor número de navíos posibles y, dentro de aquel elenco, jugó, como es lógico, un importante papel el mundo jurídico.

Durante el siglo XVIII el esfuerzo naval al que se vio obligada aquella Dilatada Monarquía requirió la sinergia de múltiples recursos, materiales y humanos, que debieron regularse mediante normativa destinada al fomento y preservación de los mismos. La Ordenanza, de 31 de enero de 1748, supuso la plasmación jurídica de las medidas tendentes a afianzar el suministro constante y perdurable de la principal materia prima empleada en la construcción de naves. Ahora bien, a pesar de lo estratégico de la madera y de la ingente actividad forestal que desarrolló la Marina, paradójicamente durante las primeras décadas de la centuria no se logró redactar 
un corpus normativo que alcanzase las diferentes regiones de la Monarquía y pudiese abarcar gran parte de los pormenores necesarios para llevar con éxito las talas y plantíos. Esto, además, se había agravado al existir lagunas normativas que propiciaron dudas a la hora de gestionar la foresta en beneficio de unos navíos que eran absolutamente imprescindibles para salvaguardar la integridad territorial hispánica, las conexiones con los territorios de Ultramar y el comercio marítimo.

La elaboración de la Ordenanza culminó gracias al ministerio de Zenón Somodevilla, marqués de la Ensenada — continuador en buena medida de la política desplegada años antes por José Patiño-, en una coyuntura crítica de inferioridad ante un posible enfrentamiento con Gran Bretaña y con una situación económica desastrosa, mediando la amenaza constante de otras potencias marítimas, y finalmente recrudecida con el estallido de una guerra, la de la Oreja de Jenkins, que planteaba una doble provocación a España en América, afectando tanto a la seguridad como a las actividades mercantiles. En este contexto, la inspección precisa de extensas masas forestales por personas al servicio de la Marina, que debían analizar meticulosamente factores silvícolas, orográficos, humanos, jurídicos y jurisdiccionales se convirtió en una necesidad de primer orden para abastecer de maderas a los tres principales arsenales de Cádiz, El Ferrol y Cartagena.

Así las cosas, la promulgación de la Ordenanza de Montes y Plantíos, de 31 de enero de 1748, supuso la aparición de una norma cuyo espíritu fue el de sistematizar y disciplinar en su totalidad las actividades silvícolas a favor de las necesidades navales de cara al exterior peninsular, pero también, en el plano interno, la confirmación documental de la pugna protagonizada por la Corona para hacerse con el aprovechamiento de una serie de montes ubicados las zonas cercanas al litoral y ríos navegables que, a pesar de haber pertenecido tradicionalmente su propiedad, uso y disfrute a otras instituciones locales y regionales quedaron desde entonces privados de ellos. En otras palabras, la Ordenanza de 31 de enero de 1748 barrió de un plumazo las jurisdicciones locales sobre la foresta, superponiendo la de la Marina a todas las demás. ${ }^{91}$

91 Se exceptuará la provincia de Guipúzcoa, que tardará un año más en tener una disposición específica sobre los montes destinados a la construcción naval. Portillo Valdés, 1981, 412-416.- AHN, Estado, 3228/4, Memorias para la Historia interior de la Marina española de nuestros tiempos apuntadas en el año de 1777: «En 28 de Junio de 1749 se expidió la Ordenanza de Montes de Guipúzcoa, para completar la de las demarcaciones de los señalados a Marina con respecto a la Ordenanza promulgada en 31 de Enero de 1748 para los de la Costa de lo demás del Reino». Sobre la transcripción de ésta, vid. Odriozola Oyarbide, 1997, documentos 15 y 16. 
En definitiva, se trató da la plasmación jurídica de que para la Monarquía española las necesidades políticas exteriores debían terminar imponiéndose a los menesteres cotidianos internos.

Recibido el 4 de febrero de 2014

Aceptado el 6 de mayo de 2014

\section{Bibliografía}

Abad León, Felipe: El marqués de la Ensenada, su vida y su obra, Madrid, Naval, 1985.

Aranda y Antón, Gaspar de: Los Bosques Flotantes. Historia de un roble del siglo XVIII, Madrid, Colección Técnica del ICONA, 1990.

Aranda y Antón, Gaspar de: La carpintería y la industria naval en el siglo XVIII, Madrid, Instituto de Historia y Cultura Naval, 1999.

Baltar Rodríguez, Juan Francisco: Las Juntas de Gobierno en la Monarquía Hispánica (siglos XVI-XVII), Madrid, Centro de Estudios Políticos y Constitucionales, 1998.

Bernardo, Pedro: Maquinas Hydraulicas de Molinos, y Herrerias, y Gobierno de los Arboles, y Montes de Vizcaya, Madrid, Oficina de Antonio Marin, 1736.

Béthencourt Massieu, Antonio de: Relaciones de España bajo Felipe V. Del Tratado de Sevilla a la Guerra con Inglaterra (1729-1739), Alicante, Asociación Española de Historia Moderna [et. al.], 1998.

Casado Rabanal, David: La Marina ilustrada. Sueño y ambición de la España del XVIII, Madrid, Ministerio de Defensa/Ediciones Antígona, 2009.

Crespo Solana, Ana: «Las reformas del comercio gaditano a comienzos del siglo XVIII en el contexto europeo de las políticas navales y comerciales», en La Casa de la Contratación y la navegación entre España y las Indias, Sevilla, Universidad de Sevilla/Consejo Superior de Investigaciones Científicas, 2004, 183-203.

Cruz Aguilar, Emilio de la: «El Negociado de Maderas de Segura en Sevilla», Historia, Instituciones y Documentos, Universidad de Sevilla, 1987, 225-274.

Díaz Ordóñez, Manuel: Amarrados al negocio. Reformismo borbónico y suministro de jarcia para la Armada Real (1675-1751), Madrid, Ministerio de Defensa, Secretaría General Técnica, 2009.

Diego García, Emilio de: «Estructuras y Organización Naval: Departamentos y Arsenales Peninsulares», Cuadernos Monográficos del Instituto de Historia y Cultura Naval, 41, Madrid, 2002, 15-39. 
Díez de Salazar Fernández, L. M.: Ferrerías de Guipúzcoa (siglos XIV-XVI), San Sebastián, Aramburu, 1983.

Fernández Duro, Cesáreo: Armada Española. Desde la unión de los Reinos de Castilla y Aragón; Madrid, Museo Naval, 1972-1973.

Fisher, J. R.: «Los cambios estructurales en la carrera de Indias en el período borbónico», Revista de Historia Naval, 47, Madrid, 1994, 21-34.

Franco Castañón, Hermenegildo, «Los apostaderos: factor esencial del apoyo naval»; Revista General de Marina, 259, Madrid, agosto-septiembre de 2009, 237-245.

García-Baquero González, Antonio: Cádiz y el Atlántico (1717-1778). (El comercio colonial español bajo el monopolio gaditano), Sevilla, Escuela de Estudios Hispano-Americanos, 1976.

Gibert y Sánchez de la Vega, Rafael: «Ordenanzas Reales de Montes en Castilla (1496-1803)», Actas del II Symposium de Historia de la Administración, Madrid, Instituto de Estudios Administrativos, 1971, 307-348.

Ibáñez de Ibero, Carlos: Historia de la Marina de Guerra española, Madrid, Espasa-Calpe, 2. ${ }^{\text {a }}$ edición, 1949.

Israel, Jonathan I.: «España y los Países Bajos españoles durante la época de Olivares (1621-1643)», en García Sanz, Ángel y Elliot, John (coords.), La España del Conde Duque de Olivares. Encuentro Internacional sobre la España del Conde Duque de Olivares celebrado en Toro los días 15-18 de septiembre de 1989, Valladolid, Universidad de Valladolid, 1990, 109-128.

Lynch, John: La España del siglo XVIII, Barcelona, Crítica, 2010.

Madoz, Pascual: Diccionario Geográfico-Estadístico-Histórico de España y sus posesiones de Ultramar, t. III, Madrid, 1847.

Martínez González, Alfredo José: «Bosques y política naval atlántica: las reformas normativas e institucionales de José Patiño (1717-1736)», Revista Hispanoamericana, 3, Cádiz, 2013, 1-26, http://revista.raha.es/13_art2.html.

Mateos Dorado, Dolores: José del Campillo y Cossio; Dos escritos políticos, Oviedo, Junta General del Principado de Asturias, 1993.

Merino Navarro, José P.: La Armada española en el siglo XVIII, Madrid, Fundación Universitaria Española, 1981.

O'Scanlan, Timoteo: Diccionario marítimo español, que además de las definiciones de las voces con sus equivalentes en francés, inglés e italiano, contiene tres vocabularios de estos idiomas con las correspondencias castellanas, Madrid, Imprenta Real, 1831.

Odriozola Oyarbide, Lourdes: La construcción naval en Gipuzkoa, siglo XVIII; Diputación Foral de Gipuzcoa, 1997.

Pérez-Crespo Muñoz, María Teresa: El Arsenal de Cartagena en el siglo XVIII, Madrid, Editorial Naval, 1992.

Pérez Fernández-Turégano, Carlos: «El Almirantazgo del Infante don Felipe (1737-1748). Conflictos competenciales con la Secretaría de Estado y del 
Despacho de Marina», Anuario de Historia del Derecho Español, 74, Madrid, 2004, 409-476.

Pérez Fernández-Turégano, Carlos: Patiño y las reformas de la Administración en el reinado de Felipe $V$, Madrid, Ministerio de Defensa, Instituto de Historia y Cultura Naval, 2006.

Perona Tomás, Dionisio: Los orígenes del Ministerio de Marina. La secretaría de Estado y del Despacho de Marina (1714-1808), Madrid, Instituto de Historia y Cultura Naval, 1999.

Portillo Valdés, José María: Monarquía y Gobierno Provincial. Poder y Constitución en las provincias vascas (1760-1808), Madrid, Centro de Estudios Constitucionales, 1991.

Quintero González, José: La Carraca. El primer arsenal ilustrado español (17171776), Madrid, Ministerio de Defensa, Instituto de Historia y Cultura Naval, 2004.

Rodríguez-Villasante, Juan Antonio: «La construcción de Arsenales durante la Ilustración. El Arsenal de Ferrol», Ciencia, Técnica y Estado en la España ilustrada, Zaragoza, Ministerio de Educación y Ciencia, 1990, 499-516.

Ruiz Torres, Pedro: Reformismo e Ilustración- Historia de España, Barcelona, Crítica/Marcial Pons, 2008.

Rumeu de Armas, Antonio: España y el mar en el siglo de Carlos III, Madrid, Marinvest, 1989.

Salas, Javier de: Marina española. Discurso Histórico, reseña de la vida de mar y Memoria en contestación a un proyecto sobre el ramo, Madrid, Imprenta de T. Fontanet, 1865.

Serrano Álvarez, José Manuel: «El gasto naval en España e Indias (1715-1759). El caso de Tierra Firme», Revista de Historia Naval, 77, Madrid, 2002, 25-34.

Urteaga, Luis: La tierra esquilmada. Ideas sobre la conservación de la naturaleza en la cultura española del siglo XVIII, Barcelona/Madrid, Ediciones del Serval/CSIC, 1987. 